\title{
Induction of Heme Oxygenase Is a Rapid, Protective Response in Rhabdomyolysis in the Rat
}

\author{
Karl A. Nath, Gyorgy Balla, Gregory M. Vercellotti, Jozsef Balla, Harry S. Jacob, Michael D. Levitt, and Mark E. Rosenberg \\ Departments of Medicine, University of Minnesota, Minneapolis, Minnesota 55455
}

\begin{abstract}
Heme proteins such as myoglobin or hemoglobin, when released into the extracellular space, can instigate tissue toxicity. Myoglobin is directly implicated in the pathogenesis of renal failure in rhabdomyolysis. In the glycerol model of this syndrome, we demonstrate that the kidney responds to such inordinate amounts of heme proteins by inducing the heme-degradative enzyme, heme oxygenase, as well as increasing the synthesis of ferritin, the major cellular repository for iron. Prior recruitment of this response with a single preinfusion of hemoglobin prevents kidney failure and drastically reduces mortality (from $100 \%$ to $14 \%$ ). Conversely, ablating this response with a competitive inhibitor of heme oxygenase exacerbates kidney dysfunction. We provide the first in vivo evidence that induction of heme oxygenase coupled to ferritin synthesis is a rapid, protective antioxidant response. Our findings suggest a therapeutic strategy for populations at a high risk for rhabdomyolysis. (J. Clin. Invest. 1992. 90:267-270.) Key words: kidney • crush syndrome • oxidants • hemoglobin • ferritin
\end{abstract}

\section{Introduction}

Organ damage may arise when heme proteins, such as myoglobin in muscle or hemoglobin in erythrocytes, escape from the intracellular space (1-7). Such heme-mediated organ injury underlies the syndrome of rhabdomyolysis, a disease instigated by muscle necrosis and dominated by kidney failure (1-7), and one that can be modeled in rats by the intramuscular injection of hypertonic glycerol $(4,5)$.

The exposure of the kidney in this syndrome to copious amounts of heme proteins led us to question whether heme oxygenase, the rate limiting enzyme in the degradation of heme (8), is induced in the kidney. In health this enzyme is mainly

Parts of this paper were presented at the American Society of Nephrologists, November 1991, and the Central Society for Clinical Research, October 1991, and have been published in abstract form (1991. J. Am. Soc. Nephrol. 2:652;1991. Clin. Res. 39:732A [abstr.])

Address reprint requests to Karl A. Nath, M.D., PO Box 736, UMHC, 516 Delaware St. SE, Minneapolis, MN 55455.

Received for publication 16 January 1992 and in revised form 16 March 1992.

1. Abbreviations used in this paper: $\mathrm{ARF}$, acute renal failure.

J. Clin. Invest.

(c) The American Society for Clinical Investigation, Inc.

$0021-9738 / 92 / 07 / 0267 / 04 \$ 2.00$

Volume 90, July 1992, 267-270 expressed in organs involved in the clearance of effete erythrocytes (8); little enzyme activity is displayed by the intact kidney. This enzyme opens the heme ring, generates biliverdin, which is converted to bilirubin. Iron is released when the heme ring is opened, while carbon monoxide is liberated (8).

Interest in heme oxygenase has been recently stimulated by the speculation that heme oxygenase may be induced in tissues in response to oxidative stress $(9,10,11)$. This thesis, so far untested in vivo, argues that the induction of heme oxygenase enables the removal of heme, a lipid-soluble, transmissible form of iron, as well as the generation of bilirubin, a metabolite with antioxidant properties (12). We reasoned that if induction of heme oxygenase represents an adaptive, protective response, then rhabdomyolysis assuredly provides a diseased state wherein the validity of this hypothesis can be tested. Moreover, we were stimulated by the observation that the intact kidney adapts to systemically administered hemoglobin by inducing heme oxygenase activity (13). We demonstrate that following rhabdomyolysis, rapid induction of heme oxygenase occurs in the kidney, and that the evocation of this response by hemoglobin before myonecrosis leads to a striking reduction in mortality. Our studies reveal the coupling of ferritin synthesis to enhanced heme oxygenase activity in vivo, a linkage thus far ignored in vivo, and one we suggest facilitates the safe sequestration of iron released as the heme ring is opened.

\section{Methods}

Glycerol model of rhabdomyolysis (glycerol acute renal failure $[A R F]$ ). This model was induced in male Sprague-Dawley rats (wt: $250-300 \mathrm{~g}$ ) deprived of water, but allowed access to rat chow (Ralston Purina Co., St. Louis, MO) overnight. $15 \mathrm{~h}$ after the removal of water, rats were injected, under ether, with $50 \%$ glycerol in water, $10 \mathrm{ml} / \mathrm{kg}$ body wt, half the volume delivered into each anterior thigh muscle $(4,5)$.

Postischemic renal failure in the rat. This model was induced by right nephrectomy and left renal artery occlusion for 45 min under methohexital anesthesia $(5 \mathrm{mg} / 100 \mathrm{~g}$ body wt given by the intraperitoneal route) (14).

RNA extraction and Northern analysis. RNA extraction, Northern analysis, and hybridization against cDNA probes were performed as detailed by Rosenberg et al. (15). The cDNAs to human heme oxygenase were obtained from Dr. Tyrrell (11), and the cDNAs to rat catalase and glutathione peroxidase were from Dr. Furata (16) and Dr. Yoshimura (17), respectively.

Determination of enzyme activity. Heme oxygenase activity was determined $6 \mathrm{~h}$ after the intramuscular injection of glycerol $(10 \mathrm{ml} / \mathrm{kg}$ body $\mathrm{wt}$ ) by two methods. We determined the generation of bilirubin by the colorimetric method (13). Kidney microsomes were incubated with hemin $(17 \mu M)$, hepatic cytosol $(3 \mathrm{mg} / \mathrm{ml})$, glucose-6-phosphate ( 2 $\mathrm{m} M)$, glucose-6-phosphate dehydrogenase $(3 \mathrm{U} / \mathrm{ml})$, and NADPH $(0.4$ $\mathrm{m} M$ ). Using gas chromatography, we also determined carbon monox- 
ide generation by kidney slices incubated overnight (18). Glutathione peroxidase and catalase activities were measured by the methods of Burk and Lawrence (19) and Aebi (20), respectively.

Renal studies: effect of prior induction of heme oxygenase. Rat hemoglobin, at a dose of $30 \mathrm{mg} / 100 \mathrm{~g}$ body wt in normal saline $(62.5$ $\mathrm{mg} / \mathrm{ml}$ ), was injected by tail vein $5 \mathrm{~h}$ before the commencement of overnight dehydration (13). Control rats received normal saline. $20 \mathrm{~h}$ after hemoglobin, all rats received an intramuscular injection of $50 \%$ glycerol, $10 \mathrm{ml} / \mathrm{kg}$ body wt and were subjected to daily serum creatinine determinations by a tail vein blood sample. In additional identically treated rats, kidneys were harvested for histology (14).

Renal functional studies: effect of inhibition of heme oxygenase. We employed a competitive inhibitor, tin protoporphyrin (21). Rats were deprived of food and water overnight for $15 \mathrm{~h}$ and injected the next morning with tin protoporphyrin, $20 \mu \mathrm{mol} / \mathrm{kg}$ body wt in $0.5 \mathrm{ml}$ of normal saline, or vehicle, subcutaneously. $3 \mathrm{~h}$ after this injection, rats were anesthetized with ether and injected with $50 \%$ glycerol, $7.5 \mathrm{ml} / \mathrm{kg}$. Identical doses of tin protoporphyrin or vehicle were given $8 \mathrm{~h}$ and $24 \mathrm{~h}$ after the first dose.

Determination of ferritin content and $m R N A$. Ferritin content in kidney cytosol was determined by an ELISA method. Kidney cytosol was prepared by the method of Diez et al. (22). The primary antibody consisted of anti-rat ferritin obtained from Dr. Hamish Munro, Massachusetts Institute of Technology, Cambridge, MA (23). The secondary antibody consisted of anti-rabbit IgG alkaline phosphatase conjugate. The sensitivity of the assay was $100 \mathrm{pg} / \mathrm{ml}$. cDNA probes for $\mathrm{H}$-ferritin and L-ferritin were obtained from Dr. Hamish Munro.

All data are expressed as means \pm SE. The unpaired Student's $t$ test was used for statistical comparisons between groups.

\section{Results}

Heme oxygenase mRNA was induced in the kidney, appearing $3 \mathrm{~h}$ after glycerol injection, attaining a 65-fold increase at $6 \mathrm{~h}$ (Fig. 1), and subsiding to a ninefold increase at $24 \mathrm{~h}$. Enzyme activity was also increased at $6 \mathrm{~h}$ (Fig. 2). Increasing doses of glycerol (2.5-12.5 ml/kg body wt) incurred similar mRNA levels at $6 \mathrm{~h}$.

We stimulated heme oxygenase by hemoglobin before provoking myolysis (activity before muscle injury: $0.228 \pm 0.037$

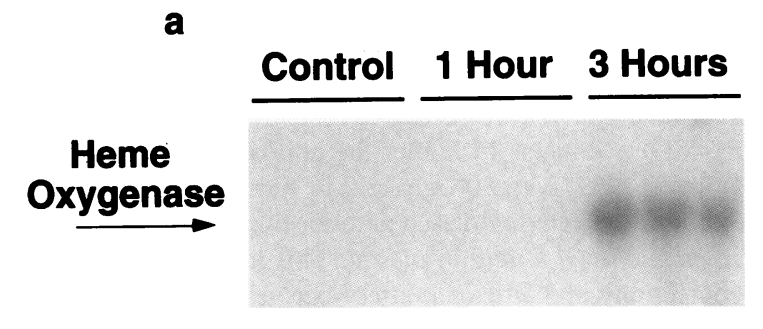

b

\section{Hours}

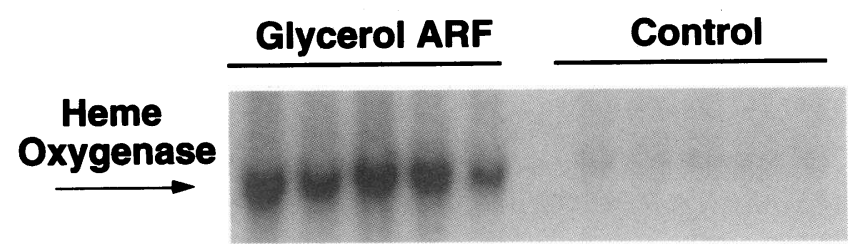

- Figure 1. Heme oxygenase mRNA in rat kidney at 0,1 and $3 \mathrm{~h}($ a) and $6 \mathrm{~h}(b)$ after intramuscular injection of glycerol $(10 \mathrm{ml} / \mathrm{kg}$ body wt). Each lane represents RNA from one kidney from an individual rat.
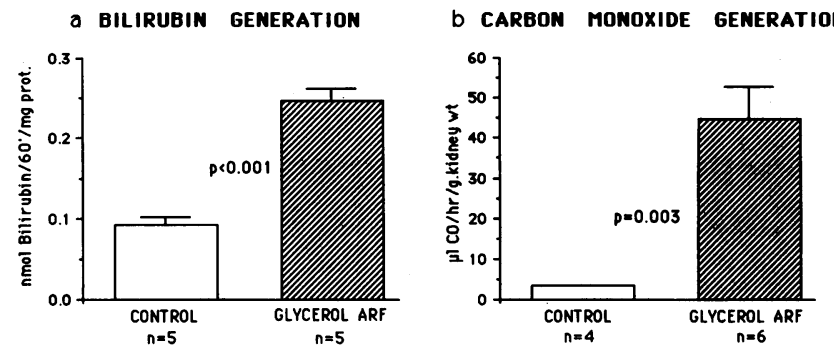

Figure 2. Heme oxygenase activity in rat kidney $6 \mathrm{~h}$ after the intramuscular injection of glycerol $(10 \mathrm{ml} / \mathrm{kg}$ body wt) determined by bilirubin generation $(a)$ and carbon monoxide generation $(b)$.

vs. $0.085 \pm 0.003 \mathrm{nmol} / \mathrm{mg}$ protein per $60 \mathrm{~min}, P<0.05)$. This exerted a striking protective effect (Fig. 3); rats pretreated with hemoglobin exhibited normal kidney function by the fifth day after myolysis, while all vehicle-treated rats died with kidney failure; mortality was reduced from $100 \%$ to $14 \%(P=0.002$ by Fischer's exact test). Hemoglobin pretreatment also reduced structural damage, as assessed by tubular necrosis and cast formation.

Porcine hemoglobin, similarly administered, also was protective (serum creatinine: $1.1 \pm 0.3$ vs. $3.9 \pm 0.5 \mathrm{mg} / \mathrm{dl}, P<0.05$, and $0.9 \pm 0.3$ vs. $6.6 \pm 0.2 \mathrm{mg} / \mathrm{dl}$ at 24 and $48 \mathrm{~h}$ after glycerol). Porcine hemoglobin, similarly administered $20 \mathrm{~h}$ previously, did not protect in the postischemic model (creatinine in treated and control rats: $2.9 \pm 0.5$ vs. $2.2 \pm 0.5 \mathrm{mg} / \mathrm{dl}$ and $2.5 \pm 1.2$ vs. $2.0 \pm 0.9 \mathrm{mg} / \mathrm{dl}, 24$ and $48 \mathrm{~h}$ after reflow).

We validated the protective role of heme oxygenase by using a competitive inhibitor of heme oxygenase (Fig. 4). In this protocol we used a lower dose of glycerol $(7.5 \mathrm{ml} / \mathrm{kg})$ because of the mortality associated with a dose of $10 \mathrm{ml} / \mathrm{kg}$. Tin protoporphyrin exacerbated kidney dysfunction in the glycerol model (Fig. 4). Tin protoporphyrin did not increase serum creatinine measured on two successive days in normal rats. Thus antagonizing the activity of heme oxygenase, induced in the kidney in this model, exacerbates kidney dysfunction.

Increased heme oxygenase activity in vitro engenders increased tissue content of ferritin $(23,24)$. We provide evidence of this same linkage in vivo. $6 \mathrm{~h}$ after myolysis, kidney content of ferritin was increased threefold (83.8 \pm 16.7 vs. $25.8 \pm 3.4, \mu \mathrm{g} /$ $\mathrm{ml}$ kidney cytosol, $P<0.05$ ), at a time when ferritin mRNA was unaltered. However, $24 \mathrm{~h}$ after myolysis, mRNAs for both ferritin species are increased, sixfold and threefold for L-ferritin and $\mathrm{H}$-ferritin, respectively (Fig. 5). That increased ferritin content may be protective in this model is suggested by studies in rats subjected to myolysis and treated with tin protoporphyrin: inhibition of heme oxygenase impairs kidney function and decreases ferritin content $24 \mathrm{~h}$ after myolysis (75.4 \pm 11.9 vs. $195.9 \pm 22.3, \mu \mathrm{g} / \mathrm{ml}$ kidney cytosol, $P=0.002$ ). Conversely, prior administration of hemoglobin is protective and increases kidney ferritin content measured just before glycerol $(95.5 \pm 16.1$ vs. $19.4 \pm 1.4, \mu \mathrm{g} / \mathrm{ml}$ kidney cytosol, $P=0.003)$.

Other antioxidants, in contrast to heme oxygenase, were suppressed in this model. Activity was diminished for catalase ( $6 h, 0.20 \pm 0.02$ vs. $0.27 \pm 0.01$ and $24 h, 0.14 \pm 0.01$ vs. $0.26 \pm 0.01, \mathrm{k} / \mathrm{mg}$ protein, $P<0.01)$ and for glutathione peroxidase ( $6 h, 67 \pm 3$ vs. $121 \pm 8$ and $24 h, 42 \pm 2$ vs. $137 \pm 2 \mathrm{nmol} / \mathrm{mg}$ protein per min, $P<0.001)$. Such diminution in activity was accompanied by a decrease in mRNA (OD units) for catalase 


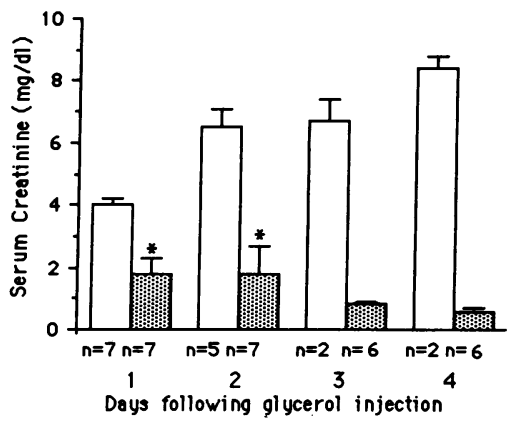

( $6 h, 495 \pm 75$ vs. $1389 \pm 152, P<0.001$, and $24 h, 275 \pm 41$ vs. $1179 \pm 74, P<0.01$ ), and a tendency for a decrement in glutathione peroxidase mRNA $(6 h, 955 \pm 77$ vs. $1892 \pm 420, P=0.06$, and $24 h, 1615 \pm 104$ vs. $1950 \pm 238, P=N S)$.

\section{Discussion}

The induction of heme oxygenase that we observed following myolysis represents an adaptive rather than a maladaptive response in that inhibition of heme oxygenase worsens renal function, while, conversely, prior induction of heme oxygenase preserves renal function and reduces mortality.

The dominance of renal dysfunction in this syndrome $(1,2)$ led us to focus on the kidney. However, it is likely that other organs also display induction of heme oxygenase. Indeed the administration of hematin or hemoglobin induces hepatic heme oxygenase activity (25). Thus the reduction in mortality achieved with prior elicitation of this response reflects the accumulated salutary effects of induction in multiple organs. It must also be pointed out that induction of heme oxygenase in nonrenal organs such as the liver and spleen would facilitate the clearance of heme proteins and thus lessen the heme burden imposed on the kidney. Conversely, inhibition of heme oxygenase would impair extrarenal degradation, thereby augmenting the quantity of heme ultimately delivered to the kidney.

The renal toxicity of heme proteins is emphasized not only in studies of myolysis but also in investigations employing systemic infusions of heme proteins $(1,3,4,5,6,7)$. Such toxicity may arise from direct vasoconstriction (1) and from the propensity of heme proteins to precipitate in urinary casts as ferric heme, especially in the reduced $\mathrm{pH}$ range that occurs with renal acidification $(6,7)$. Heme proteins also induce injury through iron-catalyzed oxidative stress $(4,5)$. In this regard, the finding

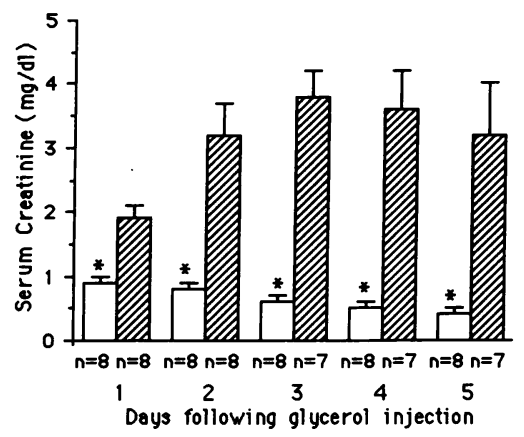

Figure 4. Functional significance of induction of heme oxygenase activity in glycerol-induced acute renal failure $(7.5 \mathrm{ml} / \mathrm{kg}$ body $\mathrm{wt})$ : effect of inhibition of heme oxygenase. $\square$, vehicle; tin protophorphyrin; ${ }^{*} P<0.005$.
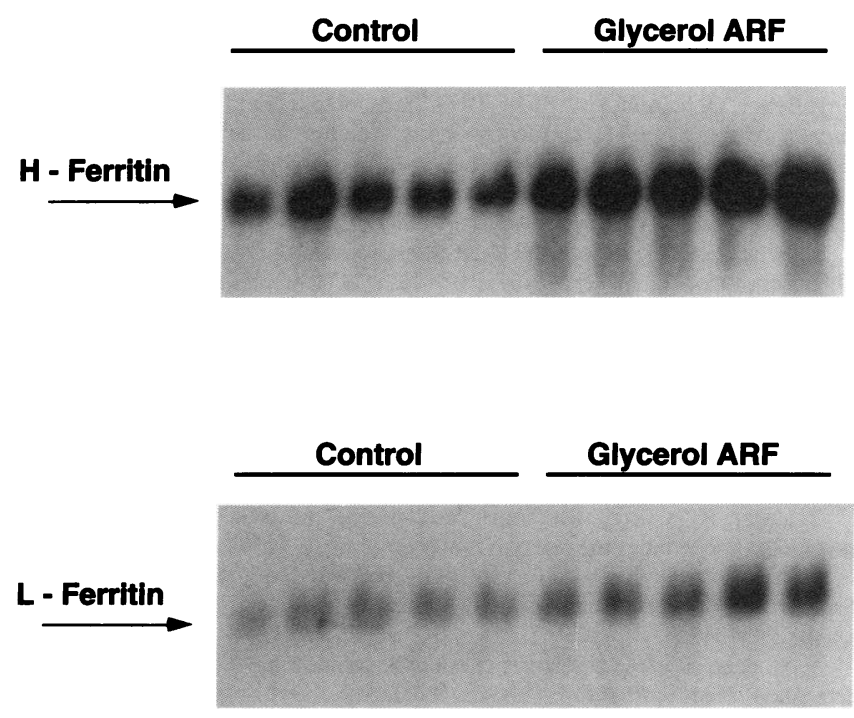

Figure 5. mRNA for L-ferritin and $\mathrm{H}$-ferritin $24 \mathrm{~h}$ after the injection of intramuscular glycerol $(10 \mathrm{ml} / \mathrm{kg}$ body $\mathrm{wt})$.

that loading endothelial cells with hemin renders these cells exquisitely sensitive to small, otherwise innocuous doses of hydrogen peroxide, is perhaps relevant to the kidney (3).

Comparatively large amounts of hydrogen peroxide are generated during normal renal oxidative metabolism $(26,27)$; such generation of hydrogen peroxide may render the kidney particularly sensitive to heme toxicity. Minimizing the amount of heme to which the kidney is exposed, by prior induction of heme oxygenase, may thus lessen injury.

Induction of heme oxygenase was accompanied by decreased catalase and glutathione peroxidase activities. Such impairment may account for the hitherto unexplained findings of Guidet and Shah that the kidney generates increased amounts of hydrogen peroxide in this model (28).

Our findings are also germane to the phenomenon of resistance to acute kidney failure (29). Kidney dysfunction following myolysis is reduced by prior treatment with endotoxin or mercuric chloride; endotoxin and mercuric salts are inducers of heme oxygenase $(8,9)$. Our findings also suggest a therapeutic strategy in patients at an inordinate risk for the crush syndrome. Finally, our data may modulate the perception of the toxicity of heme: while toxic in large amounts, heme, in small doses, is strikingly protective in vivo against organ damage and mortality inflicted by overwhelming doses of heme itself.

\section{Acknowledgments}

We express our gratitude to Dr. Munro for the cDNA probes for $\mathrm{H}$ ferritin and L-ferritin and the rat ferritin antibody (23). We thank Dr. Tyrell, Dr. Yoshimura, and Dr. Furata for the cDNA probes for heme oxygenase (11), glutathione peroxidase (17), and catalase (16), respectively.

These studies were funded by the National Institutes of Health grants R29-DK38767 to Karl A. Nath (First Award), R29-DK43075 to Mark E. Rosenberg (First Award), NLHB1-HL 33793 to Gregory M. Vercellotti, and a grant from the Graduate School, University of Minnesota, to Karl A. Nath and Mark E. Rosenberg. Mr. Anthony Croatt and Mr. David Chmielewski provided expert technical assistance. 


\section{References}

1. Better, O. S., and J. A. Stein. 1990. Early management of shock and prophylaxis of acute renal failure in traumatic rhabdomyolysis. N. Engl. J. Med. 322:825-829.

2. Gabow, P. A., W. D. Kaehny, and S. P. Kelleher. 1982. The spectrum of rhabdomyolysis. Medicine (Baltimore). 61:141-152.

3. Balla, G., G. M. Vercellotti, U. Muller-Eberhard, J. Eaton, and H. S. Jacob. 1991. Exposure of endothelial cells to free heme potentiates damage mediated by granulocytes and toxic oxygen species. Lab. Invest. 64:648-655.

4. Shah, S. V., and P. D. Walker. 1988. Evidence suggesting a role for hydroxyl radical in glycerol-induced acute renal failure. Am. J. Physiol. 255:F438-F443.

5. Paller, M. S. 1988. Hemoglobin- and myoglobin-induced acute renal failure in rats: role of iron in nephrotoxicity. Am. J. Physiol. 255:F539-F544.

6. Zager, R. A., and L. M. Gamelin. 1989. Pathogenetic mechanisms in experimental hemoglobinuric acute renal failure. Am. J. Physiol. 256:F446-F455.

7. Zager, R. A. 1989. Studies of mechanisms and protective maneuvers in myoglobinuric acute renal injury. Lab Invest. 60:619-629.

8. Abraham, N. G., J. H.-C. Lin, M. L. Schwartzman, R. D. Levere, and S Shibahara. 1988. The physiological significance of heme oxygenase. Int. J. Biochem. 20:543-558.

9. Stocker, R. 1990. Induction of haem oxygenase as a defense against oxidative stress. Free Radical Res. Comms. 9:101-112.

10. Applegate, L. A., P. Luscher, and R. M. Tyrrell. 1991. Induction of heme oxygenase: a general response to oxidant stress in cultured mammalian cells. Cancer Res. 51:974-978.

11. Keyse, S. M., and R. M. Tyrrell. 1989. Heme oxygenase is the major 32-kDa stress protein induced in human skin fibroblasts by UVA radiation, hydrogen peroxide and sodium arsenite. Proc. Natl. Acad. Sci. USA. 86:99-103.

12. Stocker, R., Y. Yamamoto, A. F. McDonagh, A. N. Glazer, and B. N. Ames. 1987. Bilirubin is an antioxidant of possible physiologic significance. Science (Wash. DC) 235:1043-1046.

13. Pimstone, N. R., P. Engel, R. Tenhunen, P. T. Seitz, H. S. Marver, and R. Schmid. 1971. Inducible heme oxygenase in the kidney: a model for the homeostatic control of hemoglobin catabolism. J. Clin. Invest. 50:2042-2050.

14. Nath, K. A., and M. S. Paller. 1990. Dietary deficiency of antioxidants exacerbates ischemic injury in the rat kidney. Kidney Int. 38:1 109-1117.

15. Rosenberg, M. E., D. Chmielewski, and T. H. Hostetter. 1990. Effect of dietary protein on rat renin and angiotensinogen gene expression. J. Clin. Invest. 85:1144-1149.
16. Furata, S., H. Hayashi, M. Hijikata, S. Miyazawa, T. Osumi, and T. Hashimoto. 1986. Complete nucleotide sequence of cDNA and deduced amino acid sequence of rat liver catalase. Proc. Natl. Acad. Sci. USA. 83:313-317.

17. Yoshimura, S., K. Takekoshi Watanabe, and Y. Fujii-Kuriyama. 1988. Determination of nucleotide sequence of cDNA coding rat glutathione peroxidase and diminished expression of the mRNA in selenium deficient rat liver. Biochem. Biophys. Res. Commun. 154:1024-1028.

18. Levitt, M. D., C. J. Ellis, and R. R. Engel. 1989. CO production by feces and urine. J. Lab. Clin. Med. 113:241-247.

19. Lawrence, R. A., and R. F. Burk. 1976. Glutathione peroxidase activity in selenium deficient rat liver. Biochem. Biophys. Res. Commun. 95:351-358.

20. Aebi, H. 1974. Catalase. In Methods of Enzymatic Analysis. H. U. Bergmeyer. editor. Academic Press, Inc., New York. 2:673-684.

21. Anderson, K. E., C. S. Simionatto, G. S. Drummond, and A. J. Kappas. 1984. Tissue distribution and disposition of tin-protoporphyrin, a potent competitive inhibitor of heme oxygenase. J. Pharmacol. Exp. Ther. 228:327-335.

22. Diez, J. M., M. T. Agapito, and J. M. Recio. 1987. Serum iron, serum ferritin and tissue ferritin during development in ducks. Comp. Biochem. Physiol. 86A:389-393.

23. Eisenstein, R. S., D. Garcia-Mayol, W. Pettingell, and H. N. Munro. 1991. Regulation of ferritin and heme oxygenase in rat fibroblasts by different forms of iron. Proc. Natl. Acad. Sci. USA. 88:688-692.

24. Balla, G., H. S. Jacob, J. Balla, M. E. Rosenberg, K. A. Nath, F. Apple, J. W. Eaton, and G. M. Vercellotti. 1991. Endothelial ferritin: a crucial defense against iron-driven oxidation. Blood. 78:396a. (Abstr.)

25. Tenhunen, R., H. S. Marver, and R. Schmid. 1970. The enzymatic catabolism of hemoglobin: stimulation of microsomal heme oxygenase by hemin. $J$. Lab. Clin. Med. 75:410-421.

26. Guidet, B. R., and S. V. Shah. 1989. In vivo generation of hydrogen peroxide by rat kidney cortex and glomeruli. Am. J. Physiol. 256 (Renal Fluid Electrolyte Physiol. 25):F158-F164.

27. Nath, K. A., and A. K. Salahudeen. 1990. Induction of renal growth and injury in the intact rat kidney by dietary deficiency of antioxidants. J. Clin. Invest. 86:1179-1192.

28. Guidet, B. and S. V. Shah. 1989. Enhanced in vivo hydrogen peroxide generation by rat kidney in glycerol-induced acute renal failure. Am. J. Physiol. 257:F440-F445.

29. Honda, N., A. Hishida, K. Ikuma, and K. Yonemura. 1987. Acquired resistance to acute renal failure. Kidney Int. 31:1233-1238. 